\title{
Bioprospecting from Biodiversity as a Development Pathway
}

\section{Isabel Martínez-Solís}

Coordinator Head Researcher of Seplan, Department of Pharmacy and Biomedical Sciences Research Institute, CEU Cardenal Herrera University, Valencia, Spain

*Corresponding author: Isabel Martínez-Solí, Coordinator Head Researcher of Seplan, Department of Pharmacy and Biomedical Sciences Research Institute, CEU Cardenal Herrera University, Valencia, Spain, Tel: 9613690 00; E-mail: isolis@uch.ceu.es

Received date: Jul 08, 2014, Accepted date: Jul 17, 2014, Publication date: Jul 31, 2014

Copyright: (c) 2014 Martínez-Solís I, This is an open-access article distributed under the terms of the Creative Commons Attribution License, which permits unrestricted use, distribution, and reproduction in any medium, provided the original author and source are credited.

\section{Editorial}

The bioprospecting is understood as the systematic search for new natural resources sources, which are biodiversity part and have potential or current economic value. The use of this term is new, but the concept has accompanied humans since the first civilizations, when they acquired consciousness of the use that they could do and the benefit that they could obtain from their environment. The indiscriminate environmental exploitation can reach endanger biodiversity, however, the rational use from resources and research on new substances and organisms are an added value in ecosystems and a further justification for preserving it, according to several articles that were published in the June issue of the business. 2020 journal (Secretariat of the Convention on Biological Diversity). Thus, biodiversity becomes more important because it will be the resource reserve in the future; the general well-being of society and its development depend on it. Also, currently the popular and ethno knowledge has a deserved importance, because it is the starting point in the current and future research on natural resources, for obtaining from medicine to energy sources.

In turn, the "protecting and conserving for using" concept can be dangerous, especially if the policies from different countries do not reach agreements for controlling the rational environmental use and the bioprospecting application. In order to policy makers and legislator can legislate and ensure the world's ecosystems safety, they must have tools. In this connection, the best tool is knowledge, especially when it derives from the serious, objective, honest and proven research. Therefore, researchers and scientists should bear in mind that publishing the research results is transcendent in one degree or another, and always important, mainly for safeguarding biodiversity and making real contribution to bioprospecting and development. In this sense, it is very important having such a multidisciplinary journal as IJBBD (International Journal of Biodiversity, Bioprospecting and Development); because it is an international forum for scientists that it enables for sharing ideas, experiences, research results and conclusions; and these can be countered, criticized and improved. In this way Science advances. Furthermore, it is a resource for new and young researchers. Politicians can also get reliable information from it. This information will be very useful for decision-making and measures' implementation.

Bioprospecting is reached in a more satisfactory way through multidisciplinary research which offers an overview of the study on new uses from substances or new substances or organisms or ecosystems. Multidisciplinary and inter-institutional teams have a great research potential. Even studies to know citizens' views, beyond the academic and scientific sphere, may be carried out for elucidating a formula for better informing entire population. So, research result dissemination is achieved, building awareness of the importance of biodiversity is also achieved. An example of this team type is the SEPLAN group; this multidisciplinary research group comprises botanists, phytochemists, and pharmacologists, specialists on human physiology, psychologists and specialists in the communication field. This group is inter-institutional and international. Its researchers belong to CEU Cardenal Herrera University (Spain), University of Valencia (Spain), CEU San Pablo University (Spain) and University of Padua (Italy); and it develops a multidisciplinary research line, whose main aim is comprehensive knowledge on plants that they can be used as medicine, food, energy source, etc., or that they are a serious problem because they can produce a health problem, such as tobacco or narcotic and hallucinogenic plants and other toxic plants.

As a senior researcher, I encourage young researchers to join and add their knowledge, resources and ideas; making multidisciplinary groups to increase their research potential in the biodiversity, bioprospecting and development field, with guidance from their senior researchers; for benefit of themselves, the scientific community and, above all, of society and its development. Finally, they should submit their scientific to multidisciplinary journals, such as this in which I am writing this editorial article. Thanks! 